\title{
Porous materials for thermal management under extreme conditions
}

\author{
By T. W. Clyne*, I. O. Golonnoy, J. C. Tan and A. E. Markaki \\ Department of Materials Science $\& 3$ Metallurgy, University of Cambridge, \\ Pembroke Street, Cambridge CB2 3QZ, UK
}

\begin{abstract}
A brief analysis is presented of how heat transfer takes place in porous materials of various types. The emphasis is on materials able to withstand extremes of temperature, gas pressure, irradiation, etc., i.e. metals and ceramics, rather than polymers. A primary aim is commonly to maximize either the thermal resistance (i.e. provide insulation) or the rate of thermal equilibration between the material and a fluid passing through it (i.e. to facilitate heat exchange). The main structural characteristics concern porosity (void content), anisotropy, pore connectivity and scale. The effect of scale is complex, since the permeability decreases as the structure is refined, but the interfacial area for fluid-solid heat exchange is, thereby, raised. The durability of the pore structure may also be an issue, with a possible disadvantage of finer scale structures being poor microstructural stability under service conditions. Finally, good mechanical properties may be required, since the development of thermal gradients, high fluid fluxes, etc. can generate substantial levels of stress. There are, thus, some complex interplays between service conditions, pore architecture/scale, fluid permeation characteristics, convective heat flow, thermal conduction and radiative heat transfer. Such interplays are illustrated with reference to three examples: (i) a thermal barrier coating in a gas turbine engine; (ii) a Space Shuttle tile; and (iii) a Stirling engine heat exchanger. Highly porous, permeable materials are often made by bonding fibres together into a network structure and much of the analysis presented here is oriented towards such materials.
\end{abstract}

Keywords: thermal barriers; heat exchangers; porous materials

\section{Introduction}

There is current interest in highly porous materials for a wide range of applications. Such materials encompass both closed-cell and open-cell geometries. Porous materials have long been of interest for heat flow management purposes, primarily either as some sort of thermal barrier or as heat exchangers. In the latter case, the main objective may be to heat/cool a component or to dissipate excess heat. It is not uncommon for the devices concerned to be regarded as structures, rather than materials, depending on the scale and regularity of the pore architecture. Their design is coming under closer study as porous materials with a range of architectures and structural scales are being developed. There is * Author for correspondence (twc10@cam.ac.uk).

One contribution of 18 to a Discussion Meeting Issue 'Engineered foams and porous materials'. 
particular interest in ceramic and metallic materials, since they can operate over a wide range of conditions, whereas polymers are often unsuitable at both high and low temperatures and may also degrade readily under high gas pressures, high irradiation fluxes, etc. Even for metals and ceramics, microstructural changes can sometimes be induced under such extreme conditions, so as to affect the thermal management characteristics. For both thermal barriers and heat exchangers, the scale and connectivity of the pores are of central importance.

In the present paper, a brief review is first presented of heat flow mechanisms in porous materials and this is followed by illustrations of how materials are tailored so as to control the heat flow in three different applications.

\section{Heat flow in porous materials}

\section{(a) Heat flow mechanisms}

A schematic representation is shown in figure 1 of the mechanisms by which heat transfer can occur in porous materials. Characteristics of conduction in solids, with electrons and/or phonons as carriers, and of radiative transmission, are described in standard sources (Siegel \& Howell 1972; Berman 1976; Klemens \& Williams 1986). Conduction in gases is also well characterized, with conductivity being dependent on the mean free path, $\lambda$, which in turn is a function of temperature and pressure (Loeb 1934) - see figure 1. At ambient temperature and pressure, $\lambda$ has a value of about $60 \mathrm{~nm}$, falling to $2 \mathrm{~nm}$ at $30 \mathrm{~atm}$ and rising to $0.4 \mu \mathrm{m}$ at $2000 \mathrm{~K}$. The gas conductivity within a pore is close to that in the free gas (e.g. $K_{\text {air }} \sim 0.025 \mathrm{~W} \mathrm{~m}^{-1} \mathrm{~K}^{-1}$ ), provided the dimensions of the pore are much larger than the mean free path $(L>\sim 10 \lambda)$. However, it falls below the free gas value if the pore structure is finer than this and can approach that due solely to gas molecule-wall collisions (Knudsen conduction) if $L$ is less than $\lambda$. This would require an exceptionally fine pore structure (unless the gas pressure is low and the temperature high), but even moderately fine structures $(L<\sim 1 \mu \mathrm{m})$ can lead to conductivities significantly below that of the free gas. Of course, all gas conductivities are normally much lower than those of solids, which usually fall between $c a 1$ and $300 \mathrm{~W} \mathrm{~m}^{-1} \mathrm{~K}^{-1}$.

The scale of the pore structure (and the grain size) can also affect radiative heat transfer, since radiation is effectively scattered by interfaces (and by grain boundaries). A fine-scale structure thus tends to result in increased scattering and reduced transmission. However, a potentially more significant effect of scale relates to the possibility of convection within or between pores (Lu et al. 1998; Lu 1999; Zhao et al. 2004). One possibility is that of recirculatory convection within closed pores. The significance of this can be gauged from Grashof number, Gr, representing the ratio of buoyancy to viscous forces, which, for the case of natural convection in closed pores of size $L$, may be evaluated from

$$
G r \approx \frac{g \Delta T L^{3} \rho^{2}}{T \eta^{2}},
$$

where $g$ is the acceleration due to gravity, $\rho$ and $\eta$ are, respectively, the density and (dynamic) viscosity of the gas, $T$ is the temperature and $\Delta T$ represents the difference in temperature within the pore. Taking a fairly arbitrary $\Delta T$ value of 


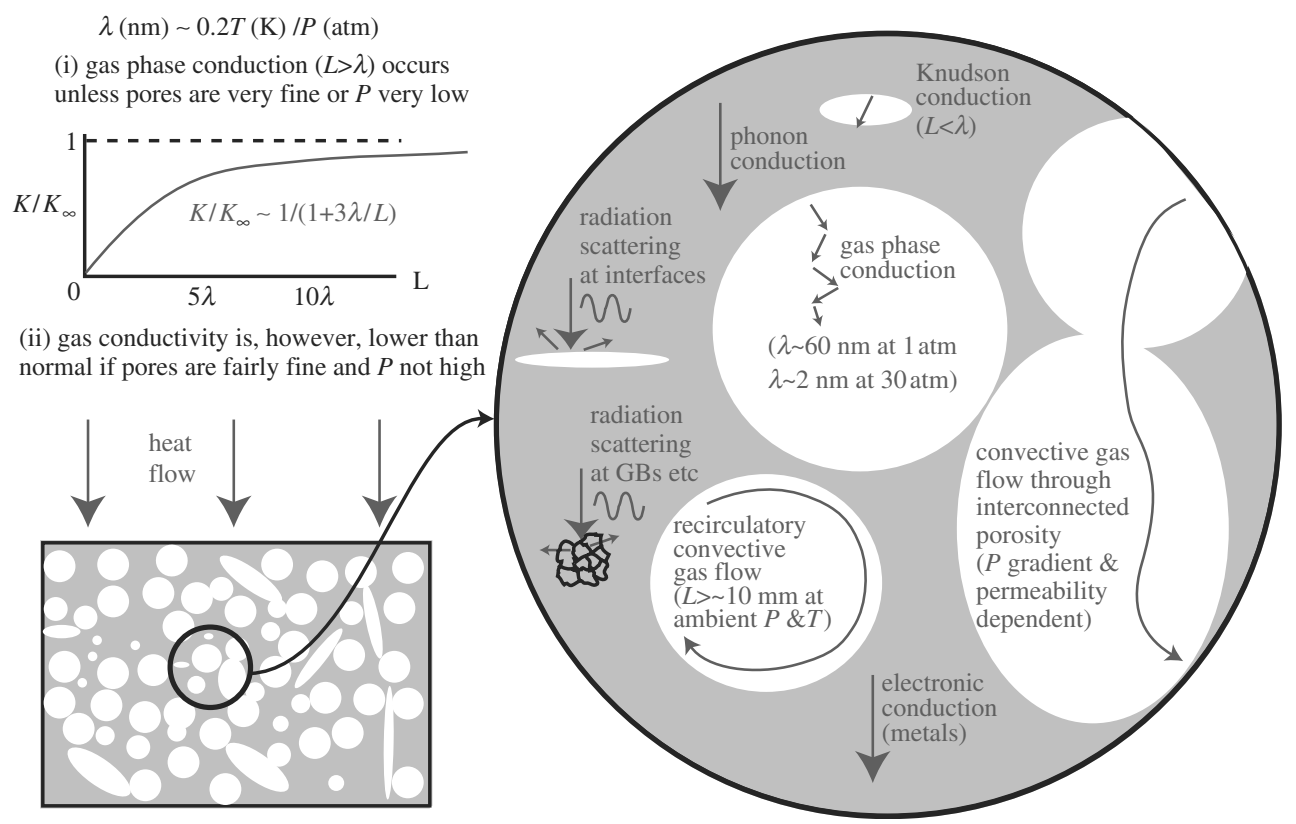

Figure 1. Mechanisms of heat transfer in porous materials.

$10 \mathrm{~K}$, the dependence of $G r$ on pore size is as shown in figure 2, for air at ambient temperature and pressure. The effects of raising the temperature and pressure are also shown. In constructing this plot, the dependence of air density on absolute temperature and pressure was assumed to conform to the gas law, so that

$$
\frac{P}{\rho T}=\text { const. }
$$

in which the constant can be evaluated from the fact that the density of air at a temperature of $273 \mathrm{~K}$ and 1 bar pressure is $1.293 \mathrm{~kg} \mathrm{~m}^{-3}$. The dependence of viscosity on temperature was assumed to follow Sutherland's equation, which for air can be written as (Weast 1984)

$$
\eta \approx 1.83 \times 10^{-5}\left(\frac{0.555(524)+120}{0.999 T+120}\right)\left(\frac{T}{524}\left(\frac{9}{5}\right)\right)^{3 / 2} .
$$

Convection is expected to be significant if the Grashof number exceeds $10^{3}$. It can be seen from figure 2 that this will only be the case when the pore size is large $(L>\sim 10 \mathrm{~mm})$. If the pressure is high (but the temperature is not), then this minimum size falls, but, in general, it can be concluded that closed-cell convection can be neglected for most porous materials, under commonly encountered conditions. In open-cell materials, on the other hand, convective heat transfer may be highly significant, depending on the connectivity and scale of the pores (see below).

\section{(b) Porous materials as composite systems}

Prediction of the effective thermal conductivity (incorporating any radiative contribution to the heat flux) is, in principle, straightforward for most composite 


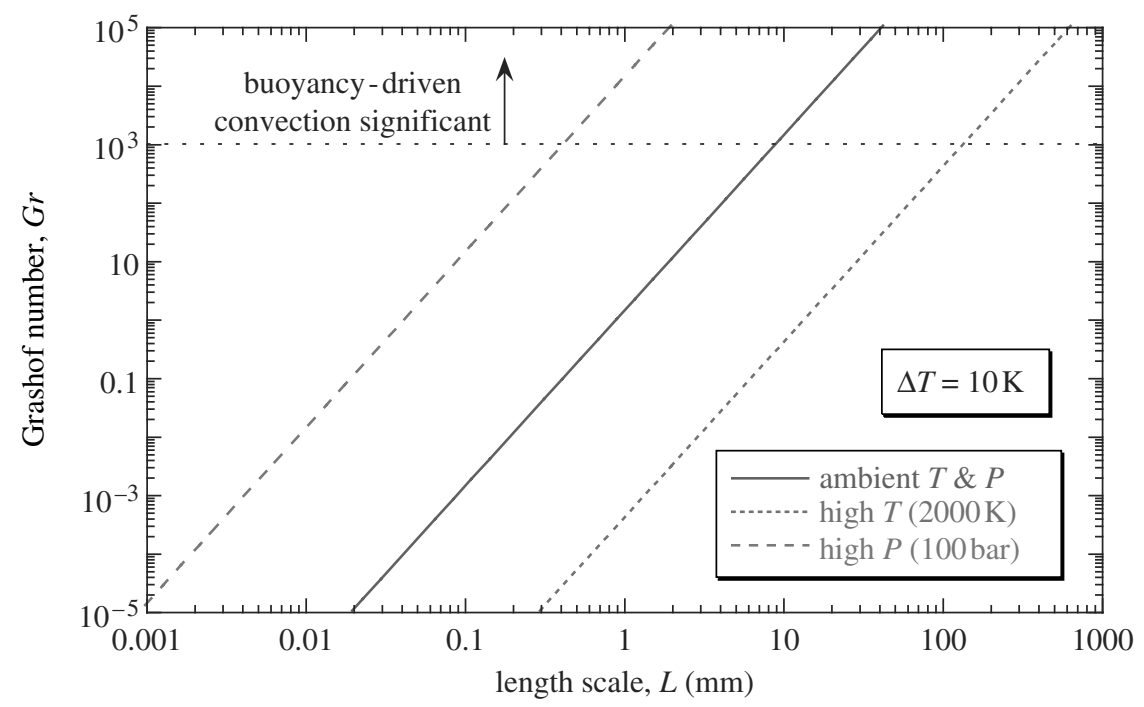

Figure 2. Dependence of Grashof number on length scale, for different pressures and temperatures.

systems, including porous materials (for which the voids, with or without gas content, can be treated as the added constituent ('reinforcement')). Various treatments (Hatta \& Taya 1986; Benveniste \& Miloh 1991; Clyne 2000) have been developed for prediction of the thermal conductivity of composites, as a function of the volume fraction and geometry of the 'reinforcing' constituent. An example is provided by the plots shown in figure 3 , which were obtained using the Eshelby method (Hatta \& Taya 1986). This leads to the following tensor equation for the conductivity in the presence of a volume fraction $p$ of insulating ellipsoid-shaped voids

$$
K=\left[K_{\mathrm{m}}^{-1}-p\left\{K_{\mathrm{m}}[S-p(S-I)]-K_{\mathrm{m}}\right\}^{-1}\right]^{-1},
$$

where $K_{\mathrm{m}}$ is the matrix conductivity, $S$ is the Eshelby tensor (dependent on ellipsoid aspect ratio $s$ ) and $I$ is the identity tensor. The plots in figure $3 a$ are for prolate ellipsoids, with aspect ratios between unity (spheres) and infinity (cylinders). It can be seen from figure $3 b$ that most porous materials exhibit conductivities below that of the Eshelby predictions. This is primarily due to inadequacies in the geometrical assumptions, since the pore architecture is in most cases more complex and convoluted than a set of isolated ellipsoids. It is in any event clear that a high void content can lead to a very low thermal conductivity ratio, but, in practice, other requirements, such as a minimum mechanical strength, may also be important.

\section{Illustrative case histories}

\section{(a) Plasma sprayed thermal barrier coating}

Thermal barrier materials are evidently designed so as to minimize their effective thermal conductivity. There are several applications, notably in gas turbine 

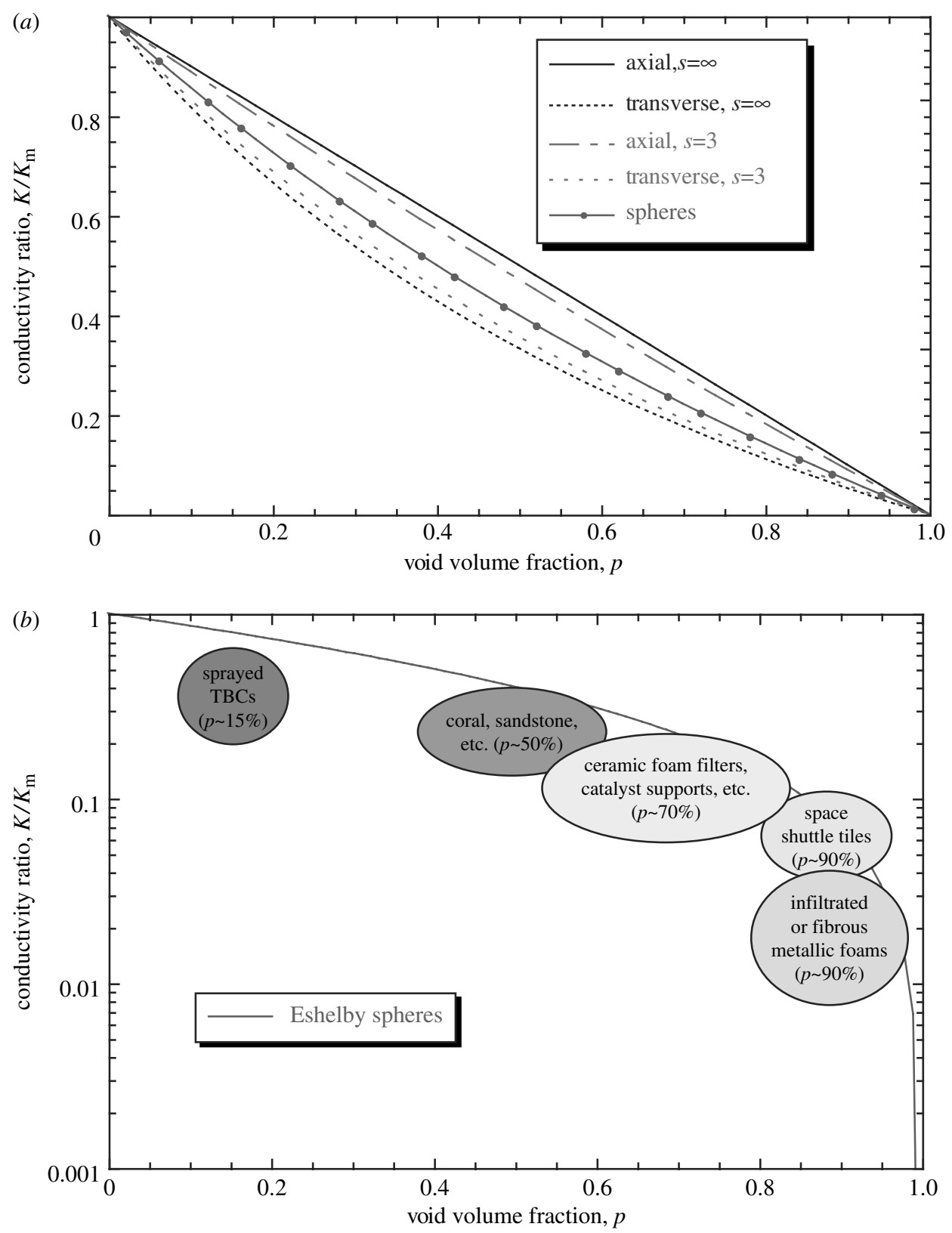

Figure 3. (a) Predicted (Eshelby) dependence of thermal conductivity (as a ratio to that of the matrix) on void content and shape, for 'composites' containing an assembly of insulating, ellipsoidal voids and $(b)$ approximate experimental data for a selection of highly porous materials, plotted together with the Eshelby prediction for spheres.

engines, for which thermal protection is highly desirable, while minimizing parasitic weight and changes to component profile. Gas temperatures at turbine entry can be as high as $1700 \mathrm{~K}$ and thermal barriers are sought giving temperature drops of $200 \mathrm{~K}$ or more. Porous materials are potentially attractive, 


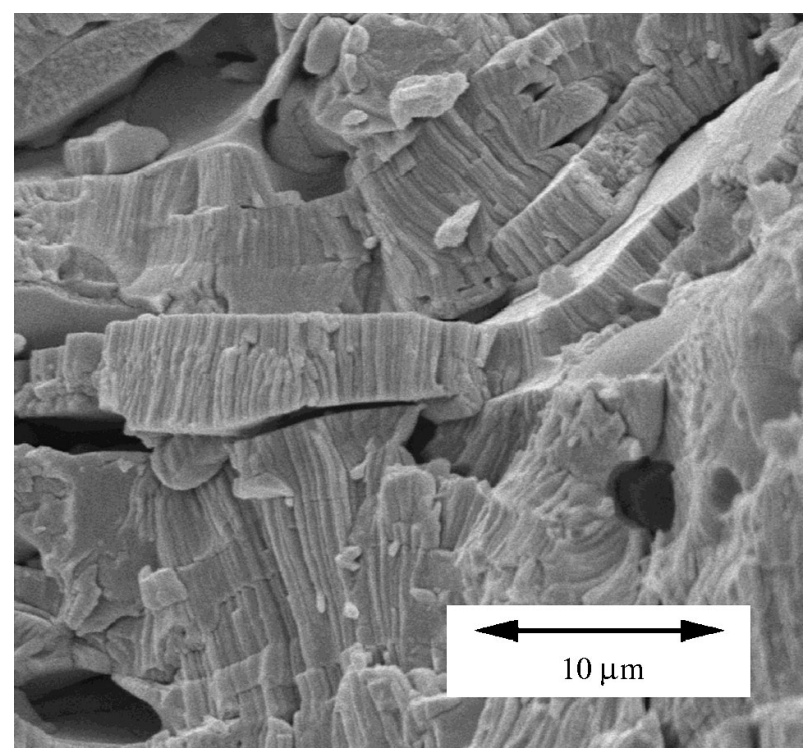

Figure 4. SEM micrograph of a plasma sprayed TBC of yttria-stabilized zirconia.

but there are several requirements in addition to low conductivity, mostly related to microstructural and thermo-mechanical stability, which can preclude materials with very high porosity levels. A wide range of base materials have been explored, and in some cases are still being considered (Clarke 2003; Stover et al. 2004), but the current industry standard for thermal barrier coatings (TBCs) in gas turbines is yttria-stabilized zirconia, deposited either by plasma spraying or by physical vapour deposition (PVD). In both cases, the porosity level is around $15 \%$. Sprayed TBCs have lower conductivities (typically quoted as around $1 \mathrm{~W} \mathrm{~m}^{-1} \mathrm{~K}^{-1}$, i.e. about $40 \%$ of the value for fully dense tetragonal polycrystalline $\mathrm{ZrO}_{2}-7 \mathrm{wt} \% \mathrm{Y}_{2} \mathrm{O}_{3}$, which is about $2.5 \mathrm{~W} \mathrm{~m}^{-1} \mathrm{~K}^{-1}$; Raghavan et al. 1998; Zhu et al. 2001), but those produced by PVD are usually regarded as mechanically more stable. Sprayed coatings are usually about $0.5-0.8 \mathrm{~mm}$ in thickness, while those produced by PVD would commonly be in the range $0.3-0.5 \mathrm{~mm}$. A drawback of PVD coatings is that their production is slow, so they tend to be relatively expensive.

Figure 4 shows a micrograph of an as-sprayed TBC. There has been extensive study (Bengtsson \& Johannesson 1995; Allen et al. 2001) of the various microstructural features exhibited by these coatings and of the changes induced under service conditions (Zhu \& Miller 1998; Trice et al. 2002; Tsipas et al. 2004) and associated alterations in conductivity and stiffness (Zhu \& Miller 2000; Thompson \& Clyne 2001). The main features are a series of interfaces parallel to the plane of the coating (normal to the heat flow direction), representing boundaries between the splats formed from incident molten droplets. These interfaces are in many cases rather poorly bonded and the associated thin gaseous layers between splats reduce the through-thickness conductivity. Fine columnar grains form during solidification, aligned normal to the plane of the coating. There has also been study (Siegel \& Spuckler 1998; Petrov \& Chernyshev 1999; Eldridge et al. 2002) of radiation transmission characteristics. The material is 

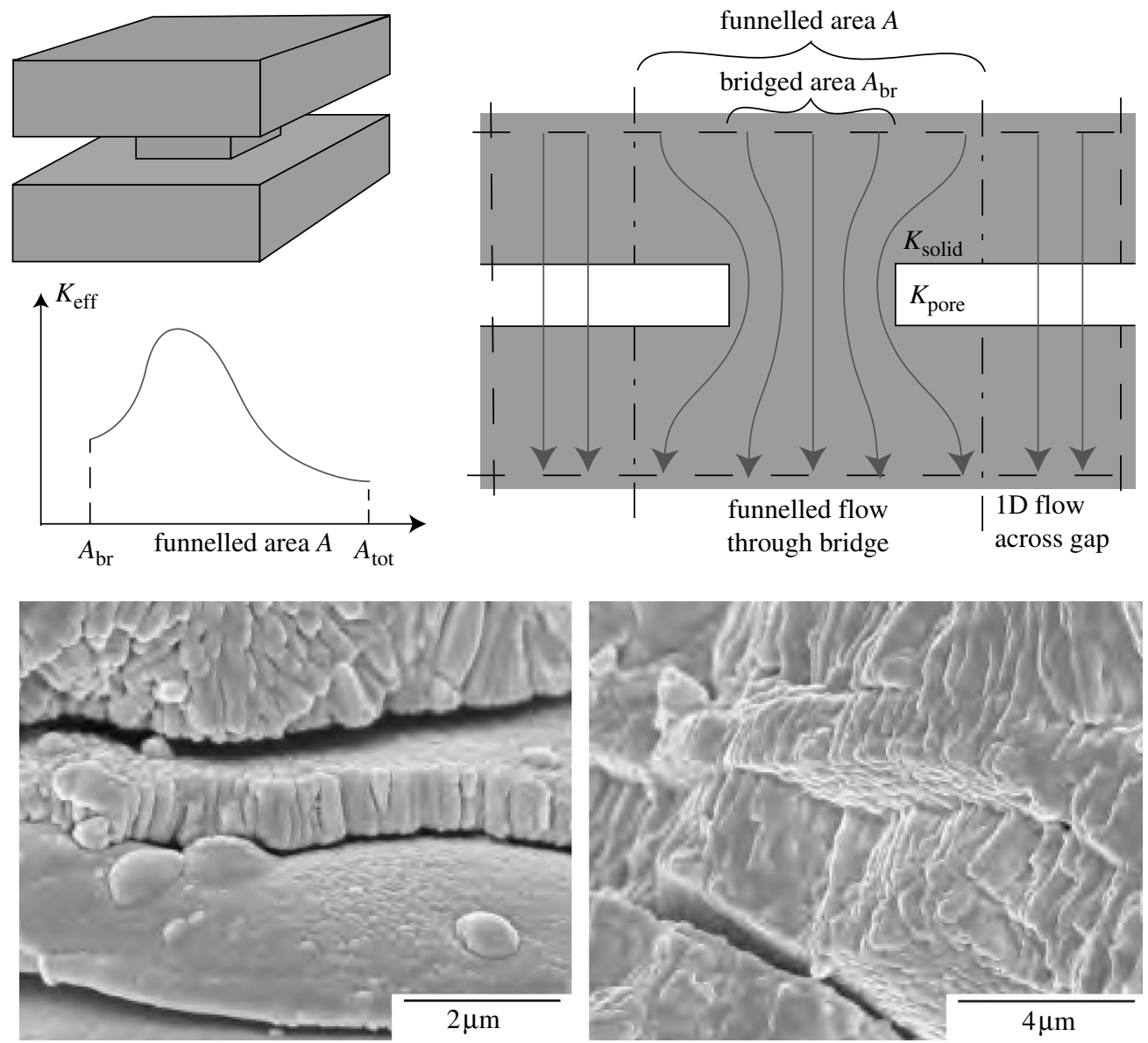

Figure 5. Schematic representation of the 'two flux regimes' model (Golosnoy et al. 2005) for heat flow through a set of plates connected via bridges, together with SEM micrographs of plasmasprayed zirconia-7\%yttria, before and after a heat treatment of $50 \mathrm{~h}$ at $1300{ }^{\circ} \mathrm{C}$.

relatively transparent to wavelengths in the near infrared part of the spectrum, although this radiation can be scattered by interfaces and grain boundaries.

A simple analytical model for the conductivity of this material, as a function of the main microstructural characteristics, has recently been developed by Golosnoy et al. (2005). The basis of this model (in which the proportionate area of a splat in contact with its neighbours is an important parameter) is illustrated in figure 5. Some predictions are shown in figure $6 b$, based on conductivity data for the two constituents shown in figure $6 a$, and compared with experimental data (Pawlowski \& Fauchais 1992; Ravichandran et al. 1999; Zhu \& Miller 2000; Trice et al. 2002). The precise conductivity of air in the inter-splat pores is predicted to have a significant effect on the overall conductivity, depending on the inter-splat bridge area. TBCs on components within the turbine region of an engine, where the gas pressure is typically about $40 \mathrm{~atm}$, may thus exhibit appreciably higher conductivities than those obtained experimentally, which are almost invariably measured at $1 \mathrm{~atm}$ pressure or 

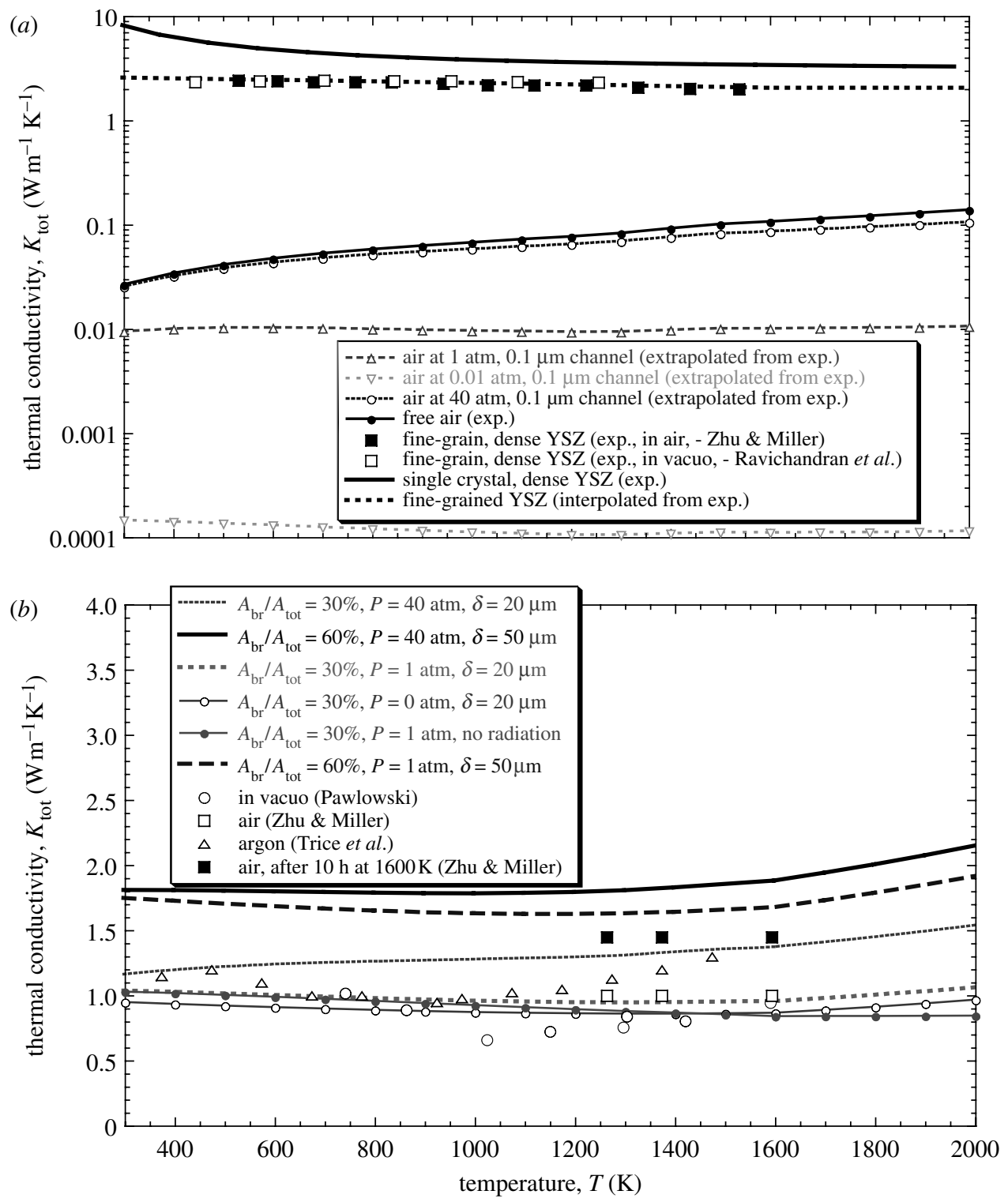

Figure 6. Conductivities of $\mathrm{ZrO}_{2}-7 \% \mathrm{Y}_{2} \mathrm{O}_{3}$, air and assemblies of the two, as a function of temperature and pressure: $(a)$ experimental data for zirconia and for free air, and deduced data for air in fine pores; and $(b)$ overall predicted and measured data, including radiative contributions.

below (Mogro-Campero et al. 1997). It is also clear that the sintering of TBCs, which can occur under service conditions (Zhu \& Miller 1998; Trice et al. 2002; Tsipas et al. 2004), raising both the inter-splat bridge area and the grain size (and hence the radiation penetration distance, $\delta$ ), can significantly increase the overall conductivity. It is worth noting, as a more general point, that, while a fine-scale structure may promote a relatively low thermal conductivity, it may also be more prone to coarsening and degradation, particularly at high temperatures. 

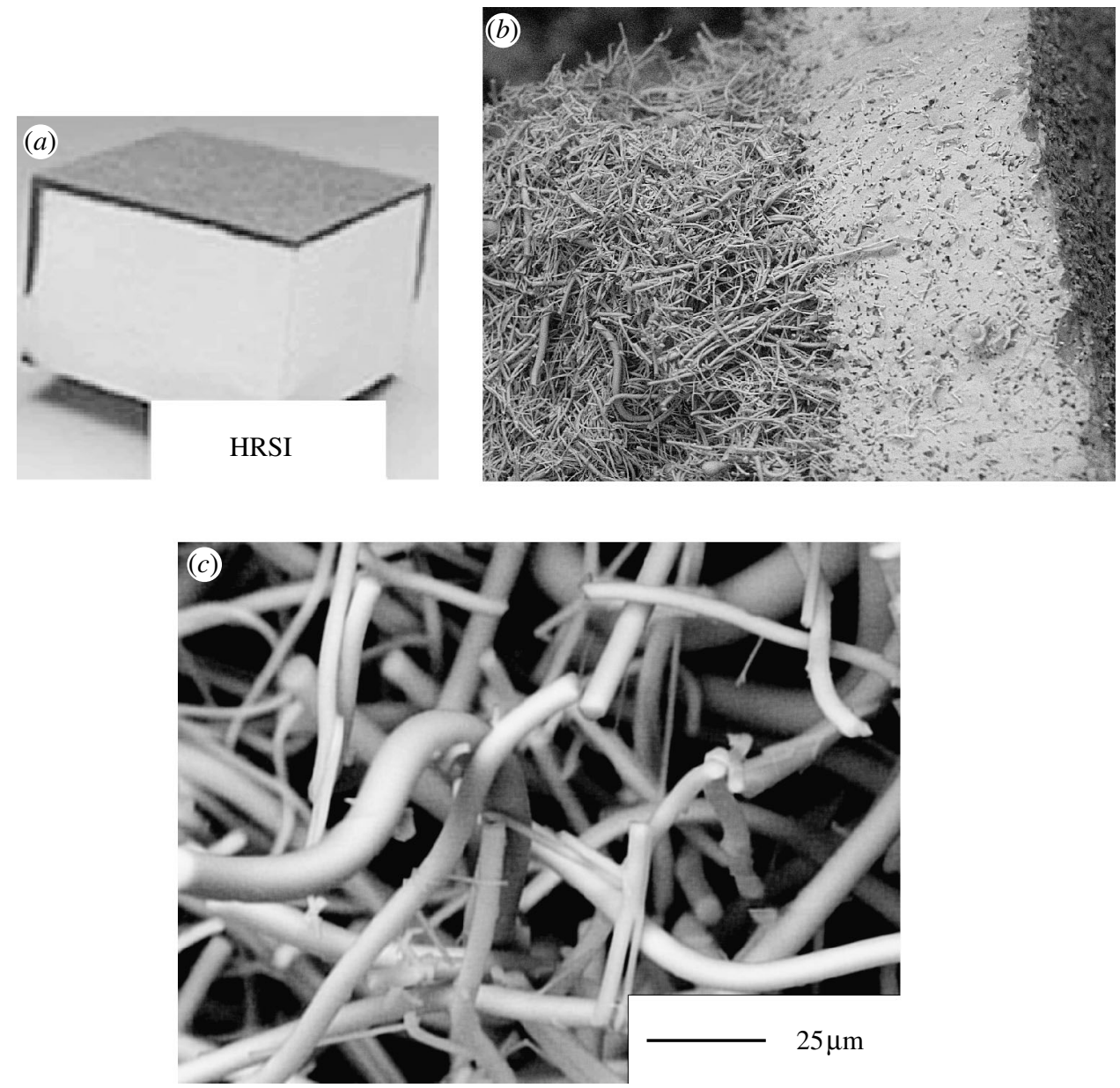

Figure 7. Structure of currently used shuttle tiles. (a) Perspective view of cut-away section, $(b)$ low magnification SEM of near-surface region and $(c)$ high magnification SEM image of interior. (Photographs courtesy of Margaret Stackpoole, NASA Ames Research Center, California.)

\section{(b) Space Shuttle tiles}

A rather different set of requirements is presented by the need to protect structural components of the Space Shuttle from overheating due to atmospheric friction during re-entry. Unlike gas turbine component TBCs, relatively thick protective layers are acceptable here, although there is a similar requirement to minimize parasitic weight. Furthermore, atmospheric pressure in pores remains low ( $c a$ less than 1 bar) and the time of exposure to high temperature is limited ( $c a$ less than $30 \mathrm{~min}$ ). Surface temperatures, however, are even higher ( $c a$ $1800 \mathrm{~K}$ ), and underlying materials (commonly aluminium) have poor high temperature durability, so that much larger temperature drops are required across these tiles than are normally generated by a TBC in a gas turbine.

Detailed design requirements and performance data are given elsewhere (Daryabeigi 2002; Nakamura \& Kai 2004). Typical tile structures are illustrated in figure 7 , although it should be noted that slightly different materials and 

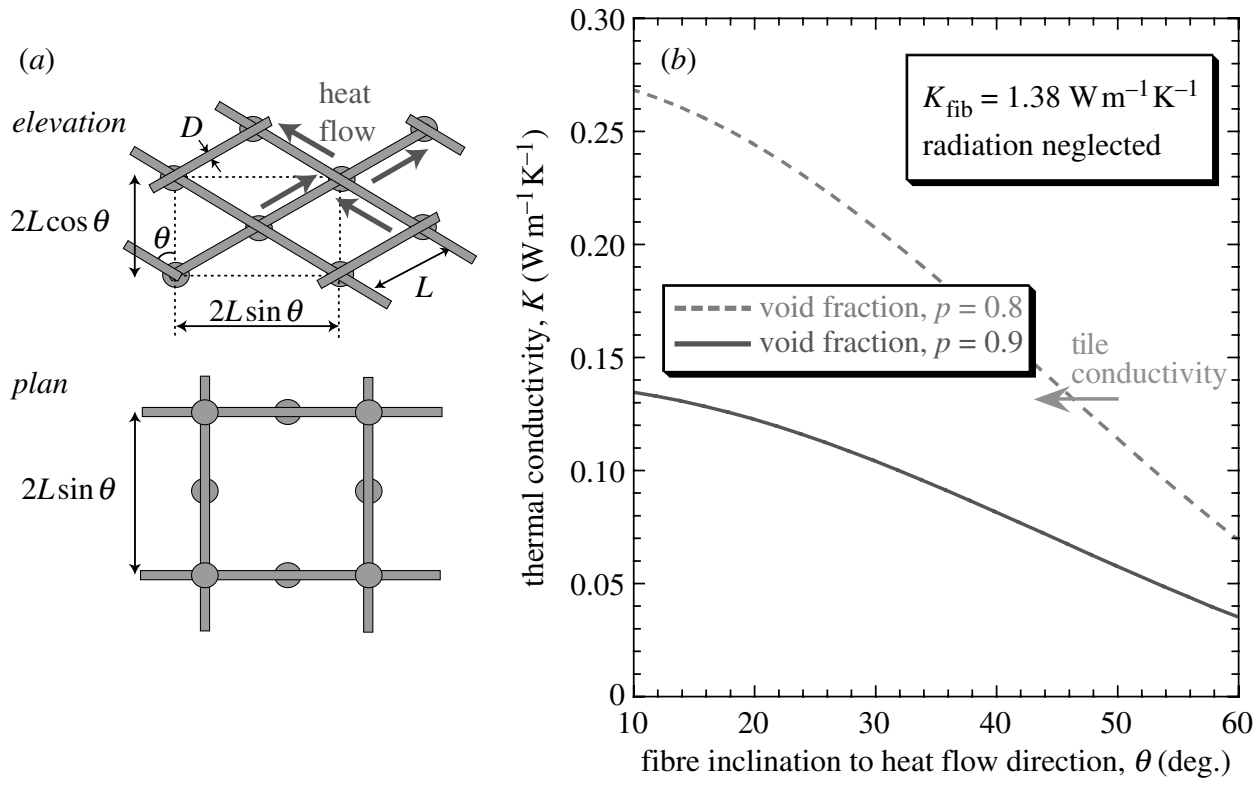

Figure 8. (a) Simple regular network model (Markaki et al. 2002) for the conductivity of a bonded fibre material and $(b)$ predicted dependence on fibre angle and void content, together with the measured value for shuttle tile material.

designs are used for protecting different parts of the spacecraft. Tile thickness is usually of the order of $70-80 \mathrm{~mm}$. The material employed is an assembly of amorphous silica fibres, held together with a colloidal silica binder. Fibre diameter is around $10 \mu \mathrm{m}$ and the porosity level is about $90 \%$. Since the air gaps between fibres are relatively large, and the gas pressure is low, conduction through the air can be neglected (even for relatively insulating fibres). Convective heat transfer is also negligible, since the tile surfaces are sealed (see figure $7 b$ ), so that there is relatively little gas flow through the fibre assembly. Radiative transfer, on the other hand, is more significant than for a $\mathrm{TBC}$, in view of the higher temperatures and lower material density (Tong \& Tien 1983; Tong et al. 1983; Petrov 1997; Lee \& Cunnington 1998, 2000; Daryabeigi 2003).

Prediction of the conductivity in an inter-connected fibre assembly is relatively straightforward. For example, if a regular network of the type illustrated in figure 8 is assumed, then it is easily shown (Markaki et al. 2002) that the conductivity is given by the equation

$$
K=K_{\text {fib }}(1-p) \cos ^{2} \theta,
$$

where $p$ is the porosity level (void content) and $\theta$ is the angle between the fibre axis and the heat flow direction. It can be seen from figure $8 b$ that the measured conductivity suggests that the average fibre inclination angle is relatively low ( $c a$ $20^{\circ}$ ), although if account is taken of a radiative contribution, then the value is probably consistent with a rather higher angle than this, which is also suggested by the micrographs in figure 7 . It is also worth noting that, while the conductivity of such a fibre assembly is predicted to be independent of fibre 
(a)

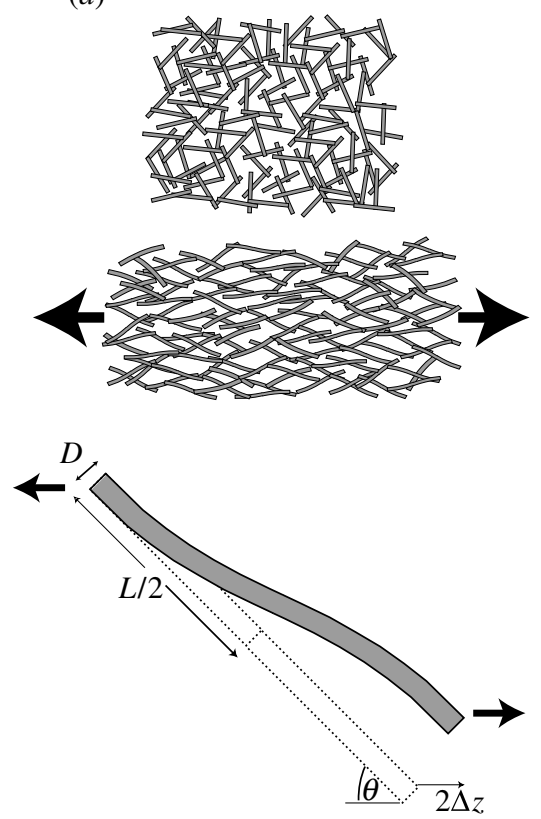

(b)

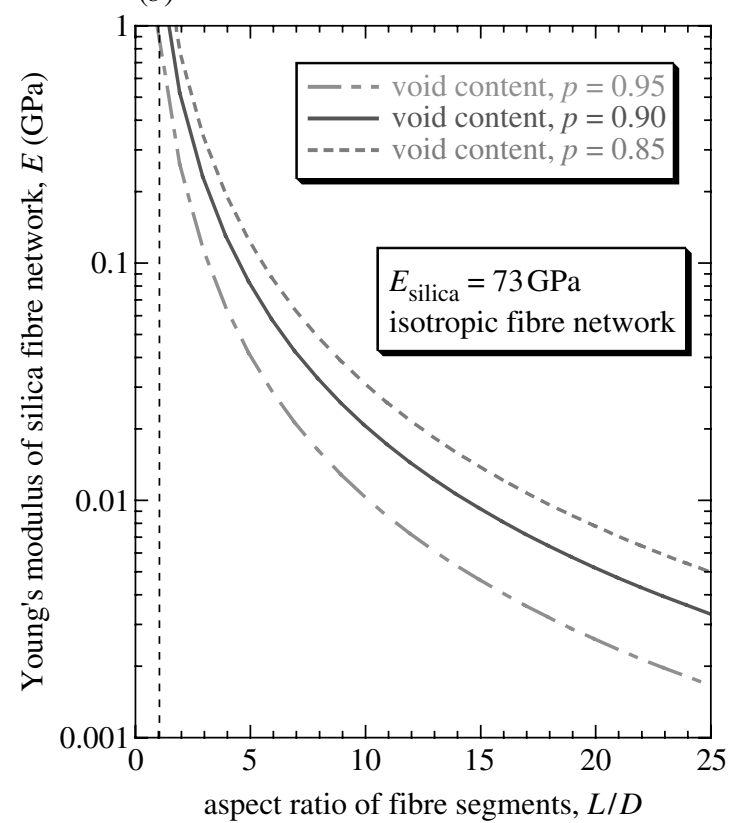

Figure 9. Stiffness predictions for shuttle tile material from a simple beam bending model (Markaki \& Clyne 2005), assuming an isotropic fibre orientation distribution: (a) geometry of model; and (b) predicted dependence of Young's modulus on fibre segment aspect ratio.

diameter, $D$, and fibre segment length $(L$ in figure $8 a$ ), its stiffness is expected to be sensitive to the segment aspect ratio, $L / D$. This can be predicted using a simple beam bending model (Markaki \& Clyne 2005), illustrated in figure $9 a$. For an isotropic fibre orientation distribution, this gives the following dependence of stiffness on $L / D$

$$
E=\frac{9 E_{\mathrm{f}}(1-p)}{32\left(\frac{L}{D}\right)^{2}},
$$

which is plotted in figure $9 b$. From micrographs such as those in figure 7 , the appropriate value of $L / D$ is of the order of 10 , so that the stiffness is expected to be around $0.01 \mathrm{GPa}$. Having such a low stiffness is beneficial in this application, since it makes the material readily conformable to substrate shape and also raises its tolerance to impact damage and to differential thermal contraction effects. Also, unlike TBCs, there is little scope for this structure to become stiffer via sintering phenomena, partly because it is not subject to prolonged exposure to high temperature, but also because the required diffusion distances are relatively large.

\section{(c) Heat exchanger}

The third example is one in which the main objective is to exchange heat rapidly with a fluid (usually a gas) flowing through a highly porous and permeable material. This also requires careful specification of structural scale, since a fine-scale structure will tend to exhibit a large internal surface area for local heat exchange, but may lead to a low permeability and hence to a slow gas 


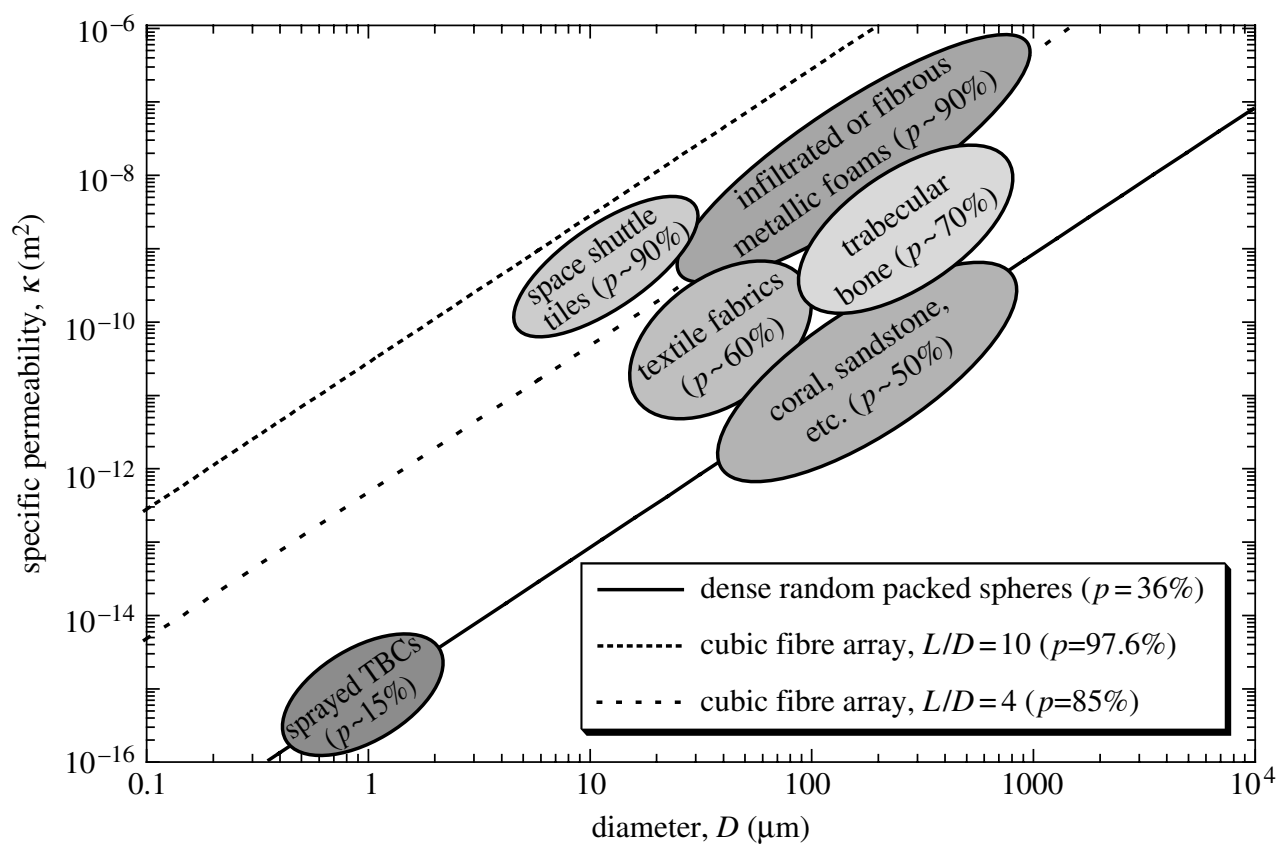

Figure 10. Semi-quantitative data for the specific permeability of various highly porous materials, as a function of length scale, together with predictions from the Blake-Kozeny equation.

flow rate. The heat transfer issues to be addressed in designing an open network structure (usually a bonded fibre assembly) of high conductivity (metallic) material have been outlined in several publications (Mantle \& Chang 1991; Lu et al. 1998; Calmidi \& Mahajan 1999; Angirasa 2002; Zhao et al. 2004).

Darcy's law, relating volumetric flow rate, $Q$, through a sectional area, $A$, to pressure gradient, $\partial P / \partial x$, and dynamic viscosity, $\eta$,

$$
\frac{Q}{A}=\frac{\kappa}{\eta} \frac{\partial P}{\partial x},
$$

defines the specific permeability, $\kappa$, which has units of $\mathrm{m}^{2}$. The value of $\kappa$ can be predicted from the architecture of the porous material, using relationships such as the Blake-Kozeny equation

$$
\kappa \approx \frac{p^{3}}{4.2 S^{2}},
$$

in which $S$, the specific surface area (surface area/total volume), can be predicted for given geometries, such as

$$
\begin{aligned}
S & \approx \frac{3.84}{D} \quad(\text { dense random packing of spheres) }, \\
S & \approx \frac{3 \pi}{D(L / D)^{2}} \approx \frac{4(1-p)}{D} \quad \text { (cubic array of fibres). }
\end{aligned}
$$

Predicted permeabilities, as a function of structural scale, obtained using equations (3.4)-(3.6), are shown in figure 10, together with some experimental data. It can be seen that these simple models are at least reliable to an order of 
(a)
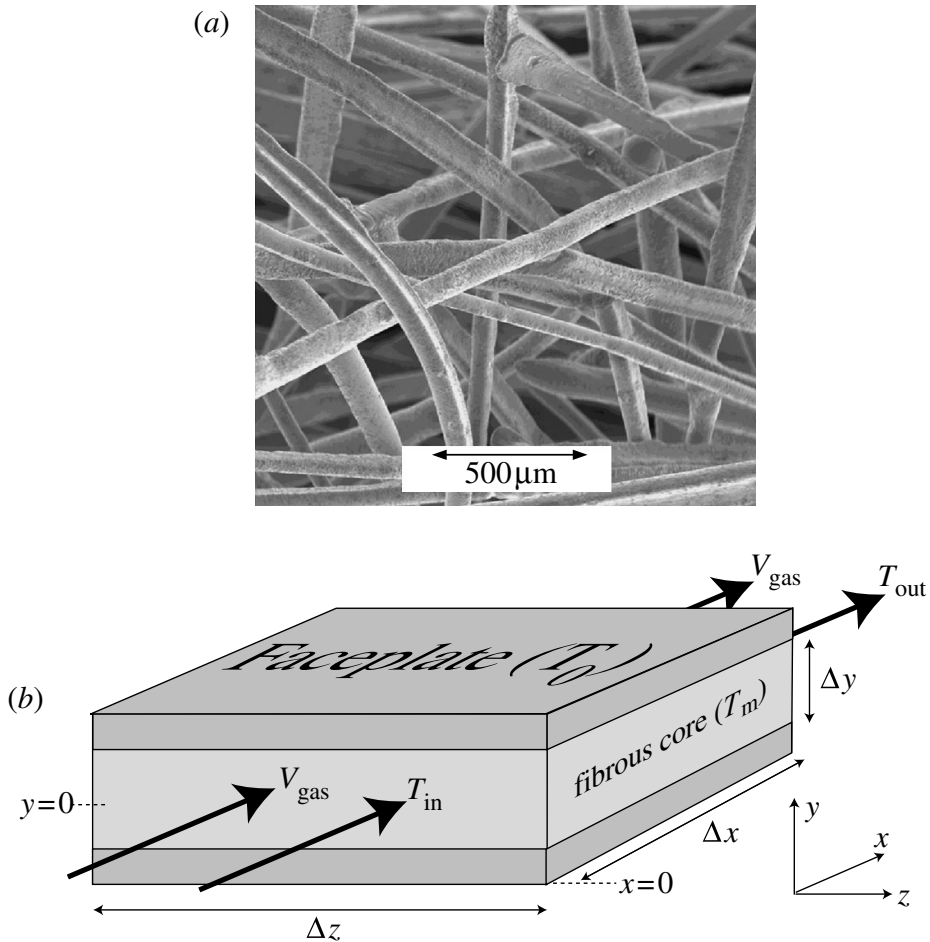

(c)

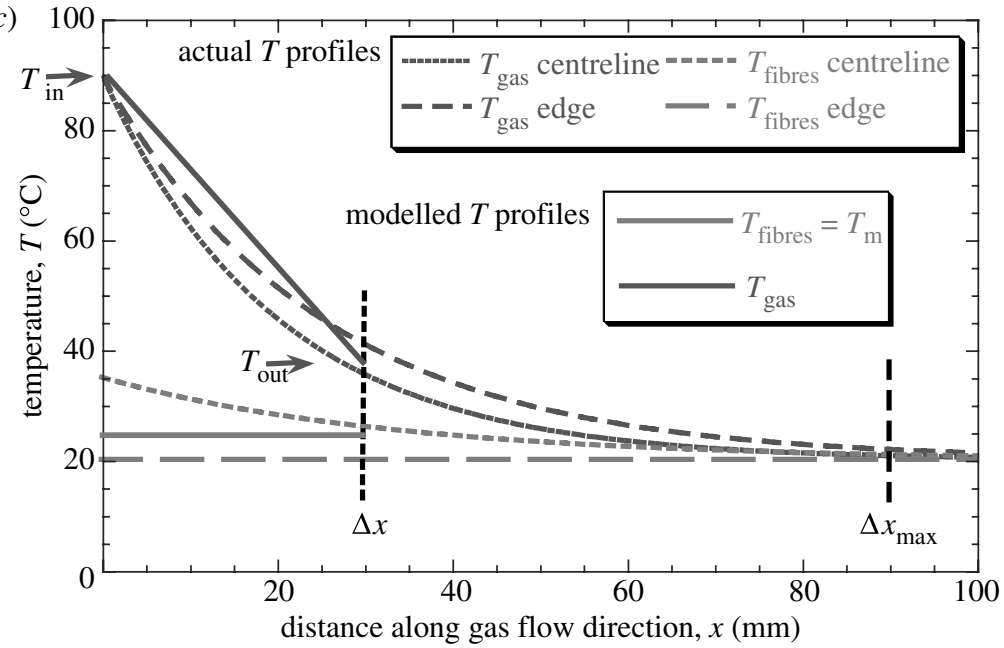

Figure 11. (a) SEM micrograph of material made by brazing of ferritic stainless steel fibres, $(b)$ schematic of a heat exchanger, with faceplates held at a constant temperature $T_{0}$ and $(c)$ representative temperature profiles along the length of the heat exchanger, showing the approximations used in the model.

magnitude. It is also clear that different materials can exhibit widely different permeabilities, depending on their void contents and structural scales.

Heat exchangers are commonly made of bonded metal fibres, giving structures of the type shown in figure 11a. It is clear that the void content and permeability must be relatively high. However, while some studies (Ashby et al. 2000) suggest 
an optimum fibre diameter (of the order of millimetres) for heat exchange efficiency, the effects of scale are complex and the issue remains largely unresolved.

A novel approach, described below, involves considering the heat flow both locally (gas-fibre) and macroscopically (through the fibre network, both normal and parallel to the gas flow direction). The model is based on obtaining three different expressions for the lateral heat flow rate, under steady conditions, and equating these. The physical system is depicted in figure $11 b$. The steady state temperature profiles along the gas flow direction ( $x$-axis) are represented in figure $11 c$.

The gas inlet temperature $\left(T_{\mathrm{in}}\right)$, and the changes in gas temperature along the length of the heat exchanger, are expected to be substantially greater than the temperatures, and temperature differences, within the fibre array. Gas/fibre heat exchange is modelled using average temperatures at a given value of $x$, approximated by

$$
\begin{gathered}
\left\langle T_{\text {gas }}(x)\right\rangle \approx 0.5\left(\left.T_{\text {gas }}\right|_{y=0}(x)+\left.T_{\text {gas }}\right|_{y= \pm 0.5 \Delta y}(x)\right), \\
\left\langle T_{\text {fibres }}(x)\right\rangle \approx 0.5\left(\left.T_{\text {fibres }}\right|_{y=0}(x)+\left.T_{\text {fibres }}\right|_{y= \pm 0.5 \Delta y}(x)\right) .
\end{gathered}
$$

The heat flow rate (in $\mathrm{W}$ ) at gas/fibre interfaces, $W_{\mathrm{i}}(x)$, is expected to be proportional to the difference between these average temperatures. It is now necessary to integrate along the $x$-axis in order to express the balance between transverse and axial heat fluxes. To do this, global average gas and fibre temperatures are defined

$$
\begin{gathered}
\left\langle T_{\text {gas }}\right\rangle=0.5\left(\left\langle T_{\text {gas }}(0)\right\rangle+\left\langle T_{\text {gas }}(\Delta x)\right\rangle\right)=0.5\left(T_{\text {in }}+T_{\text {out }}\right), \\
\left\langle T_{\text {fibres }}\right\rangle=\frac{\int_{0}^{\Delta x}\left\langle T_{\text {fibres }}(x)\right\rangle \mathrm{d} x}{\Delta x} \approx T_{\mathrm{m}} .
\end{gathered}
$$

This corresponds to approximating the temperature distributions in the $x$-direction with the linear profiles shown in figure $11 c$. (The work of $\mathrm{Lu}$ et al. (1998) suggests that this is reasonable.) It can be seen from figure $11 c$ that there is a maximum 'useful' length of the exchanger $\Delta x_{\max }$, at which the temperature of the gas approaches that of the fibres and faceplates $\left(T \sim T_{0}\right)$, so that there is little further heat exchange downstream of this point. An effective length, given by

$$
\Delta x_{\text {eff }}=\min \left\{\Delta x, \Delta x_{\max }\right\},
$$

is thus introduced, in order to indicate the distance over which heat exchange actually occurs.

Now, the transverse heat flow (in W), summed through both top and bottom faceplates, which both have an area $A_{x z}=\Delta x_{\text {eff }} \Delta z$ (see figure 11b), is given by

$$
\left.\begin{array}{l}
W_{y} \approx K_{y} \int_{0}^{\Delta x_{\text {eff }}}\left(\frac{\left.T_{\text {fibres }}(x>)\right|_{y=0.5 \Delta y}-\left.T_{\text {fibres }}\right|_{y=0}}{0.5 \Delta y}+\frac{\left.T_{\text {fibres }}(x)\right|_{y=-0.5 \Delta y}-\left.T_{\text {fibres }}\right|_{y=0}}{0.5 \Delta y}\right) \Delta z \mathrm{~d} x, \\
W_{y} \approx 2 K_{y}\left(\frac{2\left\langle T_{\text {fibres }}\right\rangle-\left.2 T_{\text {fibres }}\right|_{y=0}}{0.5 \Delta y}\right) A_{x z}=8 K_{y} \frac{\left(\left\langle T_{\text {fibres }}\right\rangle-T_{0}\right)}{\Delta y^{2}} \Delta x_{\text {eff }} A_{y z},
\end{array}\right\}
$$

in which $K_{y}$ is the thermal conductivity of the fibre network in the lateral $(y)$ direction (see equation (3.1)) and $A_{y z}=\Delta y \Delta z$. The heat flow removed from the 
gas via the fibre surfaces, $W_{\mathrm{i}}$, can be written in terms of an interfacial heat transfer coefficient, $h_{\mathrm{i}}$

$$
W_{\mathrm{i}}=h_{\mathrm{i}} \Delta T_{\mathrm{i}} A_{\mathrm{i}}=h_{\mathrm{i}}\left[\left\langle T_{\text {gas }}\right\rangle-\left\langle T_{\text {fibres }}\right\rangle\right]\left(S A_{y z} \Delta x_{\text {eff }}\right),
$$

where $A_{\mathrm{i}}$ is the fibre/gas interfacial area and $S$ is the specific surface area of the network material. Equating these two (lateral) heat flows, the following equation is derived

$$
\left[\left\langle T_{\text {gas }}\right\rangle-\left\langle T_{\text {fibres }}\right\rangle\right]=\left(\left\langle T_{\text {gas }}\right\rangle-T_{0}\right)\left[1+\frac{h_{\mathrm{i}} S \Delta y^{2}}{8 K_{y}}\right]^{-1} .
$$

Now, the heat flow lost (laterally) by the gas can be written as

$$
W_{\text {gas }}=\rho_{\text {gas }} C_{p, \text { gas }}\left(T_{\text {in }}-T_{\text {out }}\right) v_{\text {gas }} A_{y z} p,
$$

where $\rho_{\text {gas }}$ and $C_{p \text {,gas }}$ are the density and specific heat (at constant pressure) of the gas and $v_{\text {gas }}\left(=Q /\left(A_{y z} z\right)\right)$ is the gas flow velocity through the porous material. By setting this heat flow equal to $W_{\mathrm{i}}$, the following equation can be derived

$$
\left(T_{\mathrm{in}}-T_{\text {out }}\right)=\left(T_{\mathrm{in}}-T_{0}\right)\left[\frac{\rho_{\mathrm{gas}} C_{p, \mathrm{gas}} v_{\mathrm{gas}} p}{h_{\mathrm{i}}^{*} S \Delta x_{\mathrm{eff}}}+\frac{1}{2}\right]^{-1},
$$

in which

$$
h_{\mathrm{i}}^{*}=h_{\mathrm{i}}\left[1+\frac{h_{\mathrm{i}} S \Delta y^{2}}{8 K_{y}}\right]^{-1} .
$$

At this point, the specific efficiency, $\varepsilon_{\mathrm{v}}$, of the heat exchanger is introduced. This is defined as the heat exchange rate of the gas, per unit volume of exchanger. From equations (3.13)-(3.15), $\varepsilon_{\mathrm{v}}$ can be expressed in terms of the local heat transfer coefficient, which in turn can be related to the gas flow velocity.

$$
\varepsilon_{\mathrm{v}}=\frac{W_{\mathrm{gas}}}{A_{y z} \Delta x}=\left(T_{\mathrm{in}}-T_{0}\right)\left[\frac{\Delta x}{h_{\mathrm{i}}^{*} S \Delta x_{\mathrm{eff}}}+\frac{\Delta x}{2 \rho_{\mathrm{gas}} C_{p, \mathrm{gas}} v_{\mathrm{gas}} p}\right]^{-1} .
$$

The only unknown parameter in equation (3.16) is the effective depth, $\Delta x_{\text {eff }}$, which can be found from equation (3.9). The maximum operating length of the exchanger $\Delta x_{\max }$, is found by setting $T_{\text {out }}$ equal to $T_{0}$. Since $\left(T_{\mathrm{in}}-T_{0}\right)$ is equal to $\left(T_{\text {in }}-T_{\text {out }}\right)$ at this point, it follows from equation (3.14) that

$$
\Delta x_{\max }=\frac{2 \rho_{\text {gas }} C_{p, \text { gas }} v_{\text {gas }} p}{h_{\mathrm{i}}^{*} S} .
$$

Prediction of the gas flow velocity $v_{\text {gas }}$ inside the porous material is not entirely simple, since it depends on the system characteristics (e.g. the capacity of the gas pump), as well as on the properties of the heat exchange material. The relevant system characteristics can be represented in the form of a plot of pressure gradient (or pressure drop across the heat exchanger) against gas velocity through it. The actual gas velocity, $v_{*}$, is obtainable as the intersection between this line and the Darcy plot for the permeability of the heat exchanger material. This is illustrated in figure 12. If it were to be assumed that the 


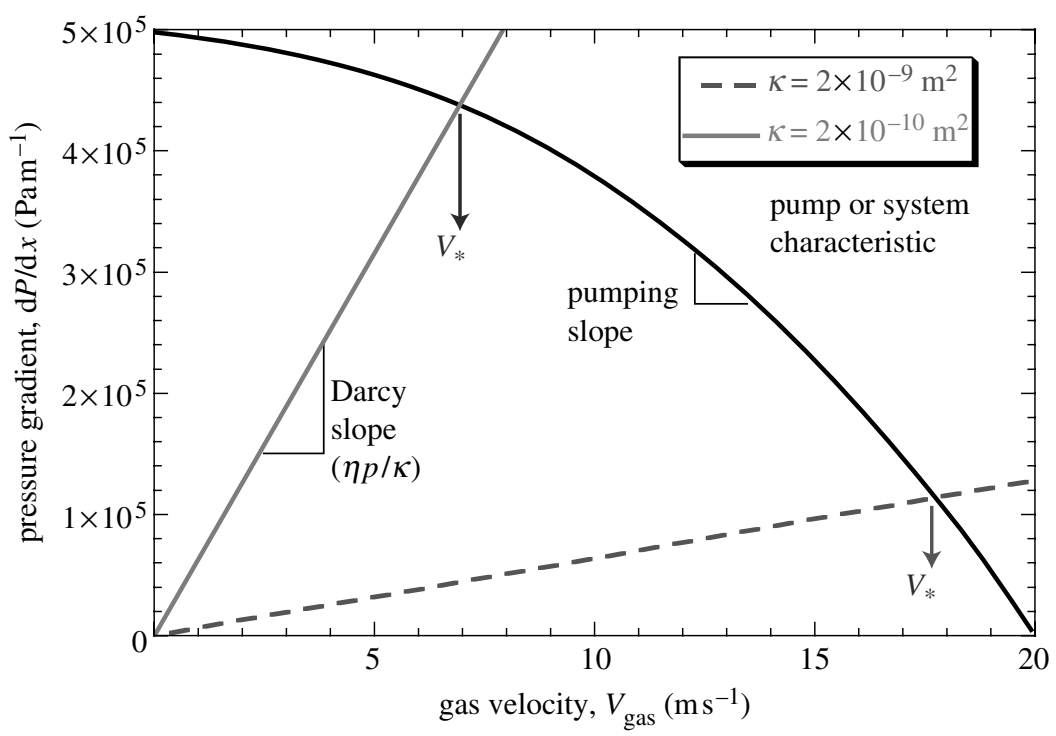

Figure 12. Semi-quantitative plot of pressure gradient (or pressure drop) against gas flow velocity, showing a possible dependence for a pumping system and corresponding actual velocities for flow through materials with two different permeabilities.

pumping system plot had a constant gradient $(=-C)$, so that

$$
\frac{\partial P}{\partial x}=\left(\frac{\partial P}{\partial x}\right)_{0}-C v_{\mathrm{gas}}
$$

then the actual gas velocity would be given by

$$
v_{\text {gas }}=\left(\frac{\partial P}{\partial x}\right)_{0}\left[\frac{\eta p}{\kappa}+C\right]^{-1} \text {. }
$$

A standard correlation expression for convective heat exchange, relating the Nusselt number to the Reynolds number and the Prandtl number,

$$
\left.\begin{array}{l}
N u \approx 0.6 \operatorname{Re}^{0.5} \operatorname{Pr}^{0.3}, \quad \text { i.e. }\left(\frac{h_{\mathrm{i}} D}{K_{\text {gas }}}\right) \approx 0.6\left(\frac{v_{\text {gas }} D}{\mu}\right)^{0.5} \operatorname{Pr}^{0.3}, \\
\therefore h_{\mathrm{i}} \approx 0.6 K_{\text {gas }}\left(\frac{v_{\text {gas }}}{D \mu}\right)^{0.5} \quad(\operatorname{Pr} \sim 0.7 \text { for gases }),
\end{array}\right\}
$$

where $\mu$ is the kinematic viscosity. This expression can now be used to evaluate the interfacial heat transfer coefficient. Substituting from equations (3.4) and (3.6) leads to

$$
h_{\mathrm{i}} \approx 0.6 K_{\text {gas }}\left[\left(\frac{\partial P}{\partial x}\right)_{0}\left\{\frac{D \mu \eta p}{\kappa}+D \mu C\right\}^{-1}\right]^{0.5} .
$$

Use of this expression allows the specific efficiency $\varepsilon_{\mathrm{v}}$ to be evaluated, together with other parameters, such as permeability and gas velocity, provided all the 

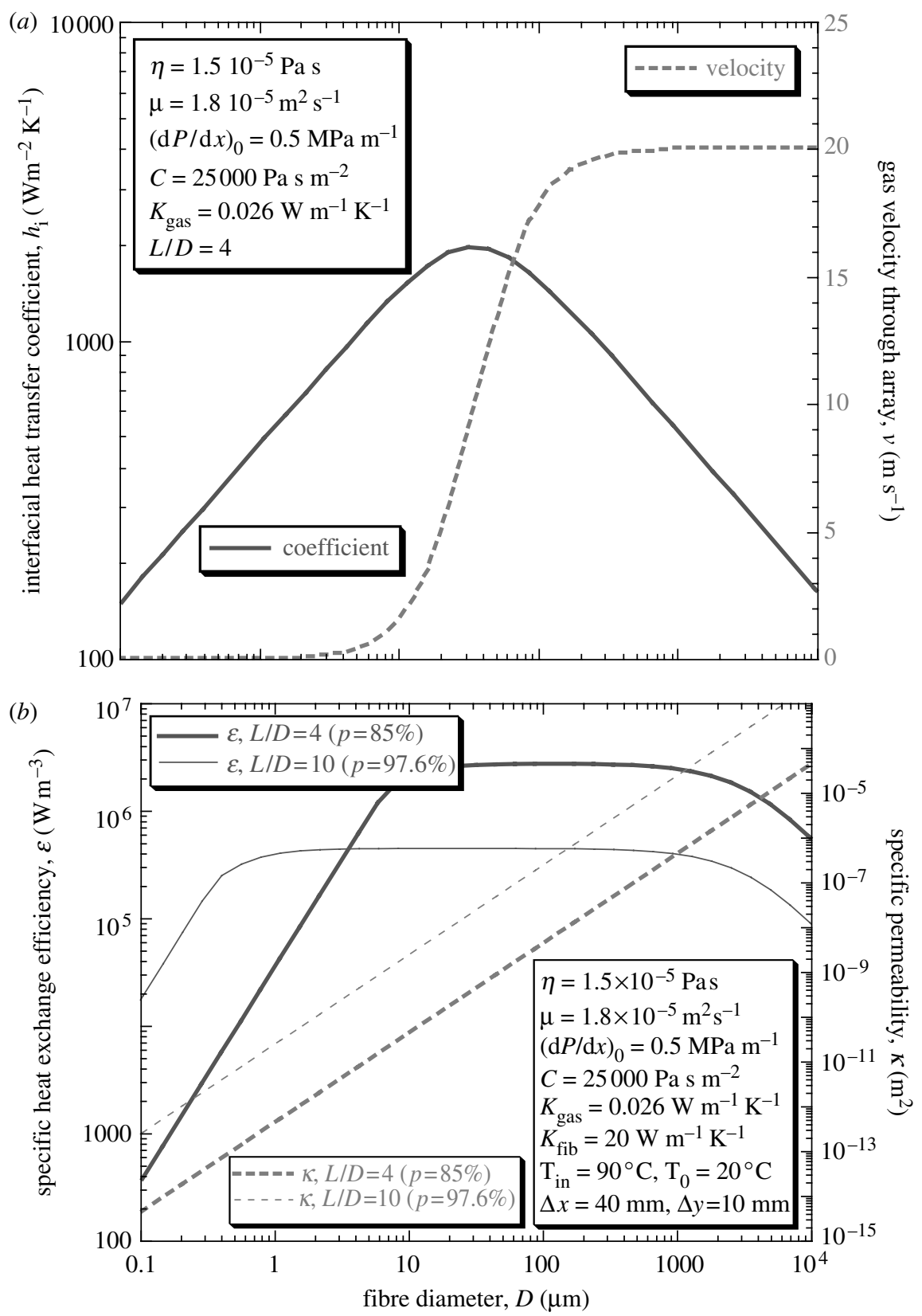

Figure 13. Semi-quantitative predicted plots of $(a)$ interfacial heat transfer coefficient and gas velocity and $(b)$ specific heat exchange efficiency and permeability, as a function of fibre diameter.

variables involved can be measured or estimated. Some illustrative data are shown in figure 13. It can be seen that both $h_{\mathrm{i}}$ and $\varepsilon_{\mathrm{v}}$ exhibit maxima at intermediate fibre diameters, although the peak is rather a flat one in the latter case. It can also be seen that the efficiency is higher for lower porosity levels, although this trend will also be reversed for denser networks, as the drop in permeability starts to become significant. 
It should be recognized that these plots are at best semi-quantitative, since values have had to be ascribed to some of the variables in a very arbitrary manner. However, the predictions indicate the approximate range of fibre diameter expected to give the most efficient operation to be about 40-200 $\mu \mathrm{m}$. It may be noted that, while very high porosities lead to lightweight structures, such networks are not very effective as heat exchangers, since they have relatively low interfacial areas and thermal conductances. An optimum porosity content is, therefore, expected, since it is clear that a very low value will lead to a low permeability and hence a low gas velocity. The value of this optimum porosity level will depend on a variety of factors, but the model presented could be used to rationalize this, as well as the role of fibre diameter.

It should also be noted that there may be other constraints. For example, finer fibres may be more prone to thermo-mechanically induced damage. On the other hand, in some applications, a heat exchanger may be required to function simultaneously as a filter for fine particulate, requiring a relatively small fibre diameter. Of course, it would be possible to mix coarse and fine fibres. In general, detailed analysis of both thermal and mechanical characteristics is required for full optimization and this is currently being tackled for various applications of this type.

\section{(d) Architectural characterization of bonded fibre assemblies}

It is clear that, in order to control and predict the properties of fibre assemblies of the type described in $\$ 3 b, c$, a quantitative technique is required for characterization of the architecture, particularly the distributions of orientation and of length (aspect ratio) of fibre segments. X-ray microtomography has now been developed (Maire et al. 2001) to a degree where it can effectively capture the three-dimensional geometry of such assemblies, provided the fibres are no finer than about $10 \mu \mathrm{m}$ in diameter. Image processing software is now routinely available for the creation of structural visualizations such as that shown in figure 14a. Recent work (Tan \& Clyne submitted) on the development and application of skeletonization algorithms to these structures has allowed the extraction of these distributions, an example of which is presented in figure $14 c$, demonstrating a tendency for fibres to lie in-plane in the material concerned. The approaches described above for prediction of thermal and mechanical properties can be adapted to incorporate such distribution functions, in either numerical or fitted analytical forms. This is an area of ongoing work.

\section{Conclusions}

The following conclusions can be drawn from the brief review of heat flow in porous materials, and the three case histories, presented here.

(i) Prediction of the thermal conductivity of porous materials generally requires an approach tailored to the scale and architecture of the pores. Even in cases where convective and radiative heat transfer can be ignored, the use of models designed for composite materials tends to be unreliable for porous materials, since the conductivity is often sensitive to pore geometry and this tends to be more complex than that of reinforcements in conventional composites. 
(a)

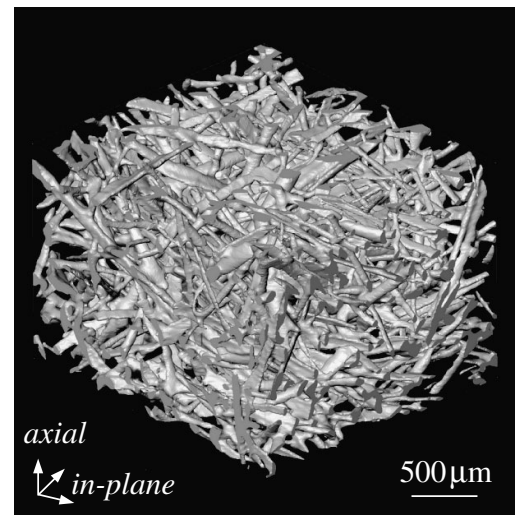

(c)

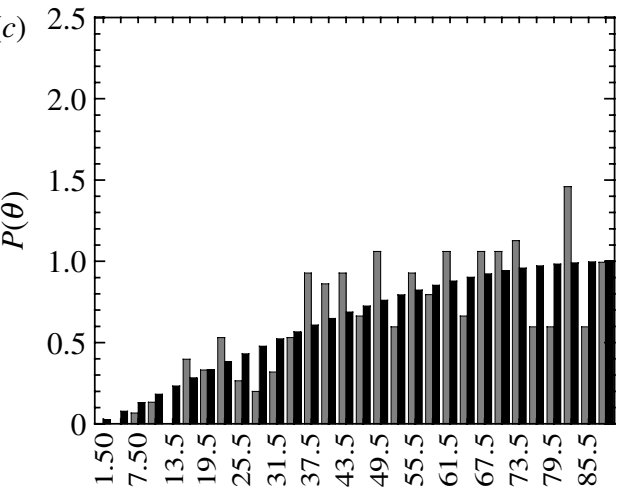

angle at centre of bin, $\theta$ (deg.) (b)

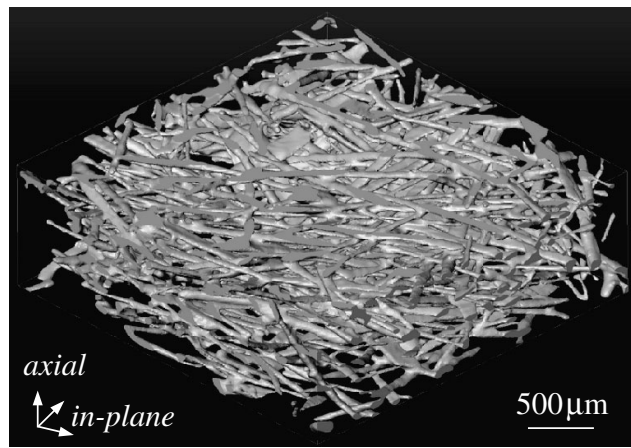

(d)

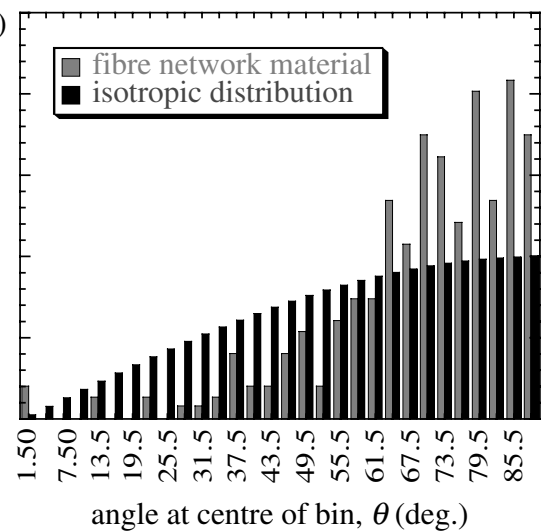

Figure 14. X-ray tomography data from two fibre network materials, produced without and with significant compression during processing, so that one is effectively isotropic and the other is not: $(a)$ and $(b)$ respectively, show topographic visualizations for isotropic and anisotropic materials, while $(c)$ and $(d)$ show corresponding histograms of fibre segment orientation distribution about the unique axis.

(ii) TBCs in gas turbines are commonly made of zirconia, with about $15 \%$ porosity content. The distribution of this porosity depends on the processing technique, but in sprayed coatings it is primarily present as thin layers oriented normal to the heat flow direction. Depending on the temperature and pressure of gas in such fine pores, its conductivity may be lower than that of corresponding free gas. Under service conditions, the net effect is predicted to be such that the conductivity is about half that of fully dense zirconia. However, structural coarsening during service, as a result of sintering effects, may lead to significant increases in this conductivity. There is also concern that such sintering may raise the stiffness of the coating, making it more vulnerable to mechanical damage and spallation.

(iii) Space Shuttle tiles are made of bonded silica fibres ( $c a 10 \mu \mathrm{m}$ diameter), with a porosity level of about 90\%. Conduction through gas in the interstitial space is negligible in this case and the conductivity can be predicted using a simple model based on heat flow paths through the fibre 
network. It is lower than that of the fibre by a factor of about 10. It also has a very low stiffness and, because the structure is relatively coarse, it is not prone to sintering effects. Unfortunately, a structure of this type would not be suitable for a TBC, since it would be unacceptably thick and it would also tend to have poor long-term erosion resistance.

(iv) Heat exchangers are commonly made of bonded metallic fibres. Porosity levels are usually similar to those in shuttle tiles, but the fibres (wires) would usually have appreciably larger diameters. Optimization of heat flow characteristics is complex, but it has been shown that there is a clear incentive to refine the fibre diameter, since this raises the interfacial area for heat exchange. On the other hand, a very fine structure will have a low permeability, leading to low gas velocities, and may also be more prone to thermo-mechanical damage. It is suggested that a fibre diameter of the order of $100 \mu \mathrm{m}$ may typically give an optimum combination of characteristics.

(v) In order to tailor the thermo-mechanical properties of bonded fibre assemblies closely to the requirements of specific applications, quantitative account will need to be taken of the three-dimensional architecture, particularly fibre axis orientation distributions and fibre segment lengths. The technique of computed X-ray microtomography, with customized skeletonization algorithms, is well suited to providing such data.

Financial support for parts of the work described in this article has come from the Cambridge-MIT Institute (CMI) and from EPSRC, via a Platform Grant. The authors are also grateful to Keith Harrison, Clive Britton, Jason Doesburg and Andrew Nicoll, of Sulzer-Metco, Margaret Stackpoole, of NASA, Richard Jones, of DSTL, Lee Marston and Peter Rooney, of Fibretech and Paolo Colombo, of Bologna University, for collaboration relevant to work described here.

\section{References}

Allen, A. J., Ilavsky, J., Long, G. G., Wallace, J. S., Berndt, C. C. \& Herman, H. 2001 Microstructural characterisation of yttria-stabilised zirconia plasma-sprayed deposits using multiple small-angle neutron scattering. Acta Mater. 49, 1661-1675. (doi:10.1016/S13596454(00)00393-1)

Angirasa, D. 2002 Forced convective heat transfer in metallic fibrous materials. J. Heat Transf. Trans. ASME 124, 739-745. (doi:10.1115/1.1470491)

Ashby, M. F., Evans, A. G., Fleck, N. A., Gibson, L. J., Hutchinson, J. W. \& Wadley, H. N. G. 2000 Metal foams: a design guide. Boston: Butterworth-Heinemann.

Bengtsson, P. \& Johannesson, T. 1995 Characterization of microstructural defects in plasmasprayed thermal barrier coatings. J. Therm. Spray Technol. 4, 245-251.

Benveniste, Y. \& Miloh, T. 1991 On the effective thermal conductivity of coated short-fiber composites. J. Appl. Phys. 69, 1337-1344. (doi:10.1063/1.347269)

Berman, R. 1976 Thermal conduction in solids. Oxford: Clarendon.

Calmidi, V. V. \& Mahajan, R. L. 1999 Effective thermal conductivity of high porosity fibrous metal foams. J. Heat Transf. Trans. ASME 121, 466-471.

Clarke, D. R. 2003 Materials selection guidelines for low thermal conductivity barrier coatings. Surf. Coat. Technol. 163-164, 67-74. (doi:10.1016/S0257-8972(02)00593-5)

Clyne, T. W. 2000 Thermal and electrical conduction in MMCs. In Comprehensive composite materials, vol. 3 (ed. T. W. Clyne). Metal matrix composites, pp. 447-468. Amsterdam: Elsevier. 
Daryabeigi, K. 2002 Thermal analysis and design optimization of multilayer insulation for reentry aerodynamic heating. J. Spacecraft Rockets 39, 509-514.

Daryabeigi, K. 2003 Heat transfer in high temperature fibrous insulation. J. Thermophys. Heat Transf. 17, 10-20.

Eldridge, J. I., Spuckler, C. M., Street, K. W. \& Markham, J. R. 2002 Infrared radiative properties of yttria-stabilized zirconia thermal barrier coatings. Ceramic and Engineering Science Proceedings, pp. 417-430. Cocoa Beach, FL: American Ceramic Society.

Golosnoy, I. O., Tsipas, S. A. \& Clyne, T. W. 2005 An analytical model for simulation of heat flow in plasma sprayed thermal barrier coatings. J. Therm. Spray Technol. 14, 205-214. (doi:10. $1361 / 10599630523764)$

Hatta, H. \& Taya, M. 1986 Thermal conductivity of coated filler composites. J. Appl. Phys. 59, 1851-1860. (doi:10.1063/1.336412)

Klemens, P. G. \& Williams, R. K. 1986 Thermal conductivity of metals and alloys. Int. Mater. Rev. 31, 197-215.

Lee, S. C. \& Cunnington, G. R. 1998 Heat transfer in fibrous insulations: comparison of theory and experiment. J. Thermophys. Heat Transf. 12, 297-303.

Lee, S. C. \& Cunnington, G. R. 2000 Conduction and radiation heat transfer in high porosity fiber thermal insulation. J. Thermophys. Heat Transf. 14, 121-136.

Loeb, L. B. 1934 The kinetic theory of gases. New York: McGraw-Hill.

Lu, T. J. 1999 Heat transfer efficiency of metal honeycombs. Int. J. Heat Mass Transf. 42, 2031-2040. (doi:10.1016/S0017-9310(98)00306-8)

Lu, T. J., Stone, H. A. \& Ashby, M. F. 1998 Heat transfer in open-cell metal foams. Acta Mater. 46, 3619-3635. (doi:10.1016/S1359-6454(98)00031-7)

Maire, E., Buffiere, J.-Y., Salvo, L., Blandin, J. J., Ludwig, W. \& Letang, J. M. 2001 On the application of X-ray microtomography in the field of materials science. Adv. Eng. Mater. 3, 539-546. (doi:10.1002/1527-2648(200108)3:8)

Mantle, W. J. \& Chang, W. S. 1991 Effective thermal conductivity of sintered metal fibers. J. Thermophys. Heat Transf. 5, 545-549.

Markaki, A. E. \& Clyne, T. W. 2005 Magneto-mechanical actuation of bonded ferromagnetic fibre arrays. Acta Mater. 53, 877-889. (doi:10.1016/j.actamat.2004.10.037)

Markaki, A. E., Westgate, S. A. \& Clyne, T. W. 2002 The stiffness and weldability of an ultra-light steel sandwich sheet material with a fibrous metal core. In Processing and properties of lightweight cellular metals and structures (ed. A. K. Ghosh, T. D. Claar \& T. H. Sanders), pp. 15-24. Seattle: TMS.

Mogro-Campero, A., Johnson, C. A., Bednarczyk, P. J., Dinwiddie, R. B. \& Wang, H. 1997 Effect of gas pressure on thermal conductivity of zirconia thermal barrier coatings. Surf. Coat. Technol. 94-995, 102-105. (doi:10.1016/S0257-8972(97)00485-4)

Nakamura, T. \& Kai, T. 2004 Combined radiation-conduction analysis and experiment of ceramic insulation for reentry vehicles. J. Thermophys. Heat Transf. 18, 24-29.

Pawlowski, L. \& Fauchais, P. 1992 Thermal transport properties of thermally sprayed coatings. Int. Mater. Rev. 37, 271-289.

Petrov, V. A. 1997 Combined radiation and conduction heat transfer in high temperature fiber thermal insulation. Int. J. Heat Mass Transf. 40, 2241-2247. (doi:10.1016/S00179310(96)00242-6)

Petrov, V. A. \& Chernyshev, A. P. 1999 Thermal-radiation properties of zirconia when heated by laser radiation up to the temperature of high-rate vaporization. High Temp. 37, 58-66.

Raghavan, S., Wang, H., Dinwiddie, R. B., Porter, W. D. \& Mayo, M. J. 1998 The effect of grain size, porosity and yttria content on the thermal conductivity of nanocrystalline zirconia. Scripta Mater. 39, 1119-1125. (doi:10.1016/S1359-6462(98)00290-5)

Ravichandran, K. S., An, K., Dutton, R. E. \& Semiatin, S. L. 1999 Thermal conductivity of plasma-sprayed monolithic and multilayer coatings of alumina and yttria-stabilized zirconia. J. Am. Ceram. Soc. 83, 673-682.

Siegel, R. \& Howell, J. R. 1972 Thermal radiation heat transfer, 1st edn. New York: McGraw-Hill. 
Siegel, R. \& Spuckler, C. M. 1998 Analysis of thermal radiation effects on temperatures in turbine engine thermal barrier coatings. Mater. Sci. Eng. A 245, 150-159. (doi:10.1016/S09215093(97)00845-9)

Stover, D., Pracht, G., Lehmann, H., Dietrich, M., Doring, J. E. \& Vassen, R. 2004 New material concepts for the next generation of plasma sprayed thermal barrier coatings. J. Therm. Spray Technol. 13, 76-83. (doi:10.1361/10599630418176)

Tan, J. C. \& Clyne, T. W. Submitted. Analysis of X-ray tomography images of bonded fibre networks to measure distributions of fibre segment length and fibre orientation.

Thompson, J. A. \& Clyne, T. W. 2001 The effect of heat treatment on the stiffness of zirconia top coats in plasma-sprayed TBCs. Acta Mater. 49, 1565-1575. (doi:10.1016/S1359-6454(01)00065-9)

Tong, T. W. \& Tien, C. L. 1983 Radiative heat transfer in fibrous insulations. Part 1. Analytical study. J. Heat Transf. Trans. ASME 105, 70-75.

Tong, T. W., Yang, Q. S. \& Tien, C. L. 1983 Radiative heat transfer in fibrous insulations. Part 2. Experimental study. J. Heat Transf. Trans. ASME 105, 76-81.

Trice, R. W., Su, Y. J., Mawdsley, J. R., Faber, K. T., De Arellano-Lopez, A. R., Wang, H. \& Porter, W. D. 2002 Effect of heat treatment on phase stability, microstructure, and thermal conductivity of plasma-sprayed YSZ. J. Mater. Sci. 37, 2359-2365. (doi:10.1023/ A:1015310509520)

Tsipas, S. A., Golosnoy, I. O., Damani, R. \& Clyne, T. W. 2004 The effect of a high thermal gradient on sintering and stiffening in the top coat of a thermal barrier coating (TBC) system. J. Therm. Spray Technol. 13, 370-376. (doi:10.1361/10599630420380)

Weast, R. C. (ed.) 1984 CRC handbook of chemistry and physics, 65th edn. Boca Raton, FL: CRC Press.

Zhao, C. Y., Kim, T., Lu, T. J. \& Hodson, H. P. 2004 Thermal transport in high porosity cellular metal foams. J. Thermophys. Heat Transf. 18, 309-317.

Zhu, D. M. \& Miller, R. A. 1998 Sintering and creep behaviour of plasma-sprayed zirconia- and hafnia-based thermal barrier coatings. Surf. Coat. Technol. 109, 114-120. (doi:10.1016/S02578972(98)00669-0)

Zhu, D. M. \& Miller, R. A. 2000 Thermal conductivity and elastic modulus evolution of thermal barrier coatings under high heat flux conditions. J. Therm. Spray Technol. 9, 175-180. (doi:10. 1361/105996300770349890)

Zhu, D., Bansal, N. P., Lee, K. N. \& Miller, R. A. 2001 Thermal conductivity of ceramic thermal barrier and environmental barrier coating materials. NASA TM-2001-211122. Cleveland, OH: NASA Lewis Research Center. 